\title{
Transfer of particulate matter from the northwestern Mediterranean continental margin: Variability and controlling factors
}

\author{
by M. Guarracino ${ }^{1}$, B. Barnier ${ }^{2}$, P. Marsaleix ${ }^{3}$, X. Durrieu de Madron ${ }^{4}$, \\ A. Monaco ${ }^{4}$, K. Escoubeyrou ${ }^{5}$ and J.-C. Marty ${ }^{6}$
}

\begin{abstract}
Long-term observations of monthly downward particle fluxes and hourly currents and temperature were initiated in 1993 in two canyons of the continental margin of the Gulf of Lion. The goals of this survey were to estimate its contribution to the $\mathrm{CO}_{2}$ global budget and to understand the role of forcing factors in the control of present-day particle exchange across this margin. A previous statistical analysis of the long-term time series suggested that variability in the transfer of particulate matter to the deep ocean could be the result of the effect of the meandering of the Northern Current and by dense water formation in winter rather than variations in the sources of matter. Numerical simulations have been carried out to consider these hypotheses. A model is used to examine the impact of local atmospheric forcing (wind stress, heat fluxes, precipitation-evaporation budget) on the variability of the oceanic circulation and of mass fluxes within the canyons from December to April, for five consecutive years between 1996 and 2001. Results show an east-west gradient of mass export on the shelf and a positive correlation between anomalies of dense water formation rates and interannual variability of particle fluxes. However, in the eastern part of the Gulf, the simulated mass export from the shelf is not significant, even during a winter of strong convection, when the measured particle fluxes are at maxima. Moreover, although the model suggests that the dense water formation could be the major hydrodynamic forcing factor, this process is not sufficient to completely explain the space and time variations of observed particle fluxes, especially at depth.
\end{abstract}

\section{Introduction}

Continental margins are buffer zones for mass exchange between the atmosphere, continents, and the open ocean and they could act as a sink of atmospheric $\mathrm{CO}_{2}$ (Liu et al.,

1. Department of Oceanography, Dalhousie University, 1355 Oxford Street, Halifax, Nova Scotia, B3H 4J1, Canada.email: maud@phys.ocean.dal.ca

2. Laboratoire des Ecoulements Geophysiques et Industriels, UMR 5519 CNRS, BP 53X, 38041 Grenoble Cedex, France.

3. Laboratoire d'Aerologie, Pole d'Oceanographie Cotiere, 14 Avenue Edouard Belin, 31400 Toulouse, France.

4. Centre de Formation et de Recherche sur l'Enviornnement Marin, UMR 5110 CNRS - University of Perpignan, 52 Avenue Paul Alduy, 66860 Perpignan Cedex, France.

5. Laboratoire d'Oceanographie Biologique, UMR 7621 CNRS - University Pierre and Marie Curie-Paris VI, BP 44, 66651 Banyuls sur Mer Cedex, France.

6. Laboratoire d'Oceanographie de Villefranche sur mer, UMR 7093, BP 28, 06234 Villefranche Sur Mer Cedex, France. 
2003). These areas make up 5\% of the global ocean and account for $20 \%$ to $50 \%$ of global primary production (Van Weering et al., 1998). They are characterized by the presence of nepheloid layers with high particulate concentrations (Monaco et al., 1987). Time series of particle flux can be obtained from long-term continuous sediment-trap records, and can be used to investigate the cycle of suspended particulate carbon at different time scales, from seasonal to interannual (Buscail, 1987; Guarracino, 2004).

Long-term records from sediment traps in the open ocean have revealed well marked seasonal cycles. The northwestern Mediterranean Sea for example is characterized by winter maxima and summer minima in particle flux (Miquel et al., 1994; Miquel and LaRosa, 1999). However the seasonal cycle can be different in other open ocean areas (Lampitt et al., 2001; Wong et al., 1999). Interannual variability in particle flux is highlighted in several long-term time series at given locations. For example in the northwestern Mediterranean Sea, a strong peak in particle flux was recorded during the winter of 1999 at the Dyfamed site (Miquel et al., 1994).

Few long-term time series are available in coastal waters, and the variability of the particle flux in such regions is rather poorly documented (Guarracino, 2004). Biscaye et al. (1994) showed that thermohaline fronts along the northwestern Atlantic margin can act as physical barriers to the export of particulate matter from the shelf and thus can influence the fate of particles produced on the shelf. In the case of the Gulf of Lion (GoL) margin, however, Klinck (1996) suggests that the effect of the bathymetry (submarine canyons) on the southwestward general cyclonic circulation may not favor shelf-slope water exchanges. In an analysis of an hourly temperature time series recorded at 1,000 m depth in the axis of the Lacaze-Duthiers Canyon, located at the west end of the GoL margin, Bethoux et al. (2002) concluded that an intense cascading event of cold water occurred at the bottom of the canyon in February/March of 1999. A numerical experiment recently highlighted the impact of prevailing atmospheric conditions on the formation of dense water in the GoL in the winter of 1999 (Dufau et al., 2004). Thus, the cascading event mentioned by Bethoux et al. (2002) could have been induced by an abnormal peak in dense water formation, as simulated by the primitive equation model of Dufau et al. (2004).

The Gulf of Lion margin is a good place to study the causes of variability in the cross-margin transfer of particulate matter. Time-series sediment trap records have been collected since $1999^{7}$ in several canyons connecting the shelf with the deep ocean, and circulation models of the GoL have been developed. Analyses of these records suggest that variability in the present-day transfer of particulate matter to the deep ocean is not caused by the sources of matter from the shelf (re-suspension, river and atmospheric inputs). Indeed, major drivers for present-day cross-shelf transfer could likely be ocean processes, such as the meandering of the Northern Current and winter dense water formation (Guarracino, 2004). The main goal of the present study is to consider these hypotheses, and

7. Suivilion-Billion oceanographic cruises led by the Centre de Formation et de Recherche sur l'Environnement Marin of University of Perpignan. 
to determine, by comparing numerical model simulations with observations, the importance of various factors controlling space and time variations of the particle flux measured in the GoL between 1996 and 2001.

Below we describe our experimental design, the numerical model, and the statistical method used for analysis. A primitive-equation modeling approach is used then to simulate the general oceanic circulation and its variability in the GoL for this period. The link between the numerical ocean circulation model and the observed particle flux is determined by computing the export of a passive tracer from the shelf. Variability in tracer export, as compared to observed particle flux, is explained through the model dynamical response. We discuss whether the long-term particle fluxes time series carried out in this experimental strategy are representative of present-day cross-shelf transfer.

\section{Material and methods}

\section{a. Background and long-term observation strategy}

i. Background. The Gulf of Lion (Fig. 1) is a mid-latitude temperate deltaic margin with a large flat outer shelf. The slope is steep and cut by several (about 10) submarine canyons (Berne et al., 2002). The Rhone River is the most important river in the Mediterranean Sea (average flow of $1700 \mathrm{~m}^{3} / \mathrm{s}$ ) since the damming of the Nile and supplies a large amount of suspended material to the shelf. The shelf is also fed from several Mediterranean rivers that reach $10 \%$ of the Rhone inputs during the highest flood periods (Ludwig, unpublished data).

The Gulf of Lion is subject to intense atmospheric forcing by strong, cold continental winter winds (Tramontane and Mistral) blowing from the northwest. Strong gales from the southeast alternate with these continental winds and blow preferentially during fall. These atmospheric conditions have various impacts on the hydrodynamics (Millot, 1990). The role of the wind stress curl on the shelf oceanic circulation of the Gulf of Lion has been highlighted previously (Estournel et al., 2003).

A general cyclonic circulation is defined by the Northern Current (also called the Liguro-Provençal Current), which flows southwestward along the continental slope (Fig. 1). The velocity of the Northern Current is between $30 \mathrm{~cm} \mathrm{~s}^{-1}$ and $50 \mathrm{~cm} \mathrm{~s}^{-1}$ at the surface, decreasing with depth. The Northern Current can reach almost 2,000 m depth at the entrance of the Gulf of Lion. The mesoscale variability of the Northern Current is associated with meanders as it flows close to the continental slope off Marseille(Conan et al., 1995; Sammari et al., 1995).

ii. Experimental plan. Particle flux data have been continuously collected since October 1993 at two submarine canyons (Fig. 1): Planier Canyon to the Northeast [43.02 N, 05.11 E] and Lacaze-Duthiers canyon to the Southwest [42.26N, 03.33E]. With regard to the large-scale cyclonic circulation of the North Current, the Planier Canyon is located at the entrance of the GoL, and the Lacaze-Duthiers canyon is located at the exit of the GoL 


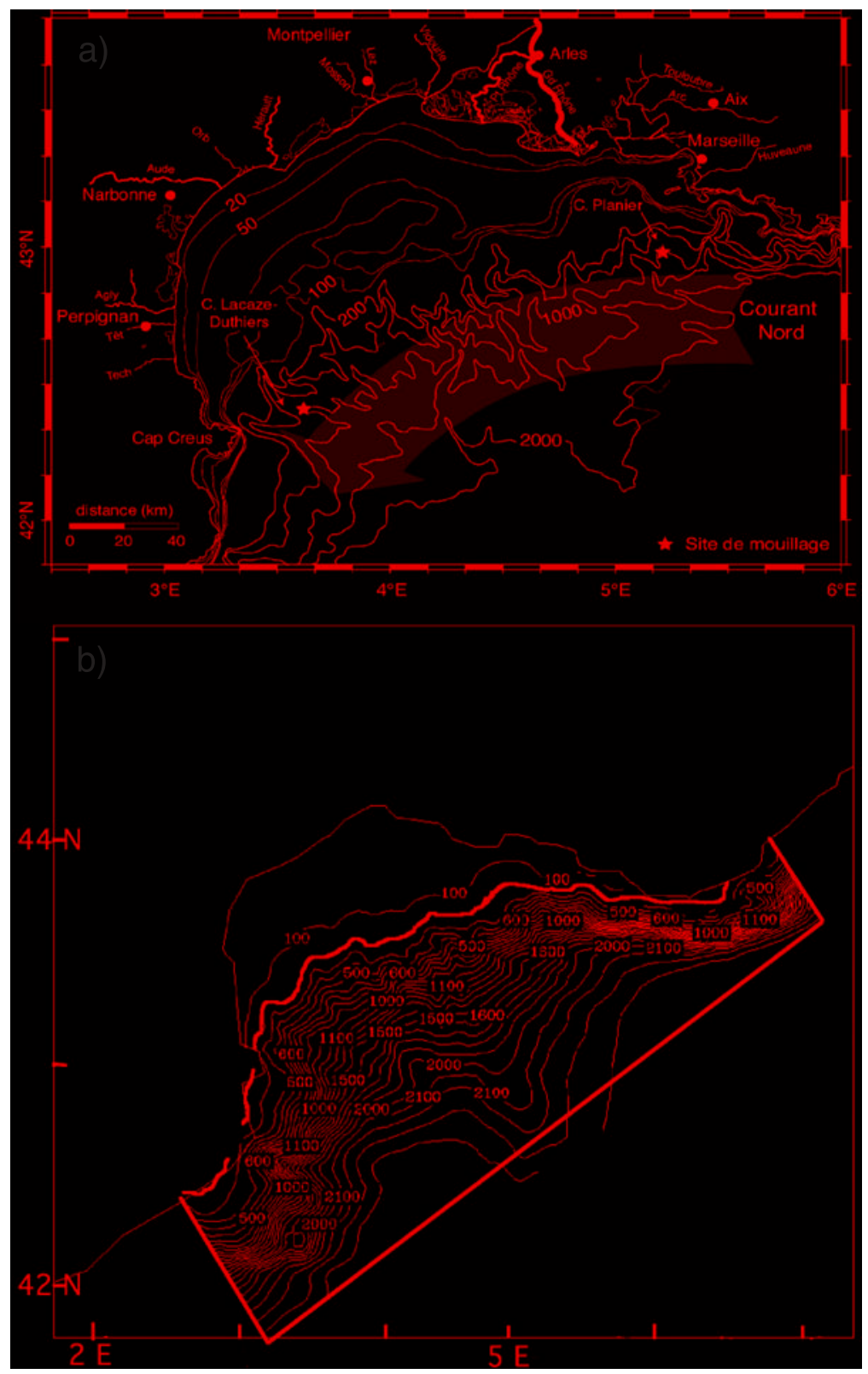

Figure 1. The Gulf of Lion's continental margin is represented in (a) and black stars stand for the locations of studied submarine canyons. The Symphonie bathymetry used in the modeling approach is represented in (b). In the second figure the black lines define the open ocean boundaries of the Symphonie model. The bold black line represents the $150 \mathrm{~m}$ isobath used to bound the offshore tracer concentrations in our experiments. 


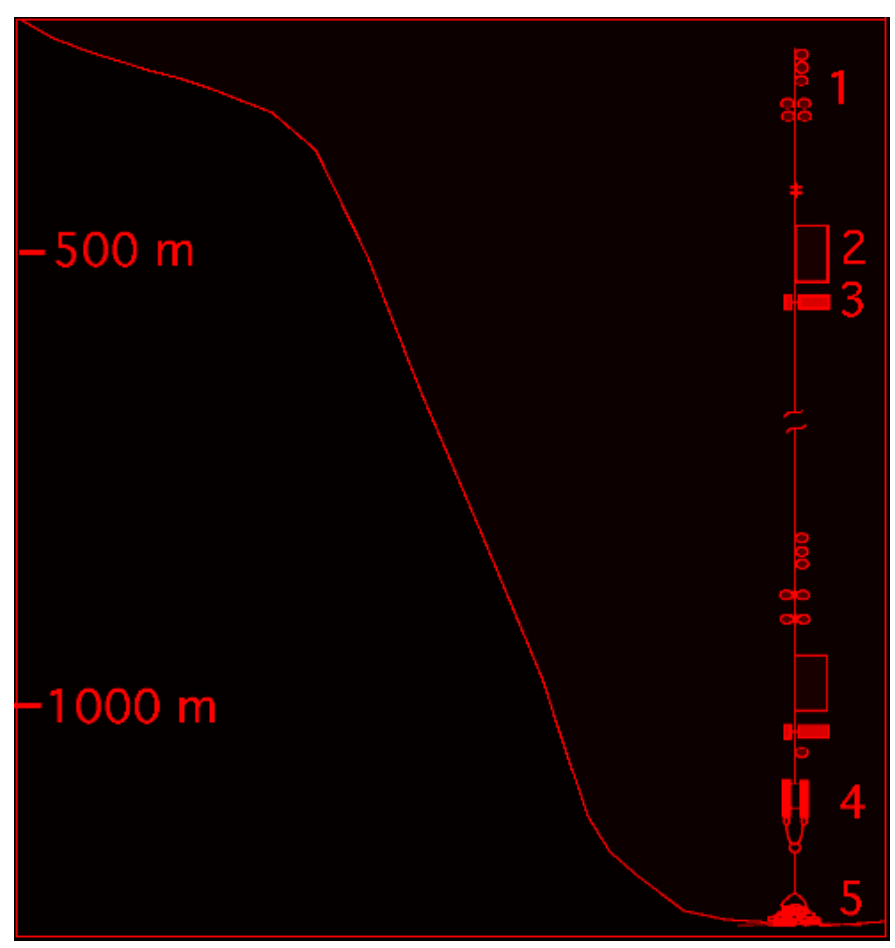

Figure 2. The experimental strategy chosen by the Centre de Formation et de Recherche sur l'Environnement Marin (CEFREM) to study the transfer of the particulate matter from the shelf to the slope on a long time scale. A mooring line is composed by glassed buoys (1), PPS 3 sediment traps located at $500 \mathrm{~m}$ (2) and 1,000 m depth (4), Aanderraa current-meters RCM with thermistor (3: $500 \mathrm{~m}$ depth, 5: 1,000 $\mathrm{m}$ depth), an acoustic release system (6), and weight (7) to maintain it since the bottom of the sea. Two mooring lines have been placed in the Gulf of Lion's continental margin. The scientists of the CEFREM conceived the experimental strategy. The technical staff of the CEFREM carried out the samples collection and their treatment.

(Monaco et al., 1999). The distance between observation points should enable characterization of the spatial variability of the transfer from the shelf to the slope of particulate organic carbon. The length of the records, from 1993 to present, can be used to characterize temporal variability.

The experimental array used to collect these data is described in Figure 2. Mooring lines were placed in the axis of the canyons. Recorded observations are monthly for total downward fluxes of particulate matter and hourly for current velocities and temperature at $500 \mathrm{~m}$ (middle of the water column of the open slope) and at $1000 \mathrm{~m}$ (i.e. 30 meter above bottom).

Sediment traps samples were processed according to Heussner et al. (1990). Major constituents (opal, organic matter, carbonates and lithogenic fraction) of the mass flux were defined according to Heussner et al. (1990) and Monaco et al. (1987). 
Hydrodynamic bias was detected during winter periods for deeper traps (1996 at the entrance and 1999 at the exit). Furthermore the shape of the sediment traps used in this experiment does not allow for formation of a quiet bottom layer of the trap, which is important to the particles trap processing (US JGOFS, 1989). This implies that the comparison between the particle fluxes observed and the simulated export of tracer from the shelf can only be qualitative.

\section{b. Modeling approach}

i. Gulf of Lion Model. A primitive-equation modeling approach is used to simulate the general oceanic circulation and its variability in the Gulf of Lion. The evolution of a passive tracer is computed along with the hydrodynamic model integration. The quantity of tracer exported from the shelf is here considered as a substitute for the particle flux which can then be compared to the observed particle flux.

The model used to simulate the circulation in the GoL and its variability is the 3-D, sigma-coordinate, full primitive equation model Symphonie. The ability of this model to simulate the hydrodynamics and hydrology of the Gulf of Lion was demonstrated by Estournel et al. (2003) and Dufau et al. (2004). We use the same geographical domain and the same configuration and model set-up as these authors (Fig. 1). The horizontal grid is rotated counterclockwise by $31^{\circ}$, such that the main axis of the domain follows the main orientation of the continental slope. The horizontal grid size is $3 \mathrm{~km}$, and the vertical resolution is defined with 26 generalized sigma levels (the number of grid points is $124 \times 74 \times 26$ ). Although the model bathymetry is smoothed (a requirement for sigma coordinate models), the submarine canyons are still well defined. The horizontal viscosity coefficient is $15 \mathrm{~m}^{2} \mathrm{~s}^{-1}$.

The atmospheric parameters describing surface forcing (wind stress, heat flux, evaporation and precipitation) are obtained from 6 hourly analyses of the Arpege model of Météo-France (Déqué et al., 1994). They have been bi-linearly interpolated onto the model grid. Daily freshwater supply data are used for the major rivers: Grand-Rhone and Petit-Rhone, Aude, Agly, Herault, Tet and Tech (Fig. 1a).

Methods for initialization and specification of the open ocean boundary conditions of the GoL model configuration are described in Dufau et al. (2004). The fields required are horizontal velocity, temperature and salinity fields, and free surface elevation. These were obtained from a multi-year experiment carried out with a $1 / 8^{\circ}$ ocean general circulation model of the Mediterranean Sea (the MOM model, Dufau et al., 2004). Since all experiments carried out in this study start in December (see below), the 1998 December mean of the MOM model solution was extracted, and used as initial conditions and also to drive the open boundaries. Consequently, water inflow properties do not vary with time at the open boundaries. Seasonal variability of the Northern Current is not represented at the eastern boundary; however, the effects of the variability in river floods (especially the Rhone River) on the shelf circulation are included in this configuration. For these reasons, 
Table 1. Characteristics of the experiments carried out with the GoL model

Experiment name

Winter96

Winter97

Winter98

Winter99

Winter00

Winter01

Climatic
Start

January 1996

December 1997

December 1998

December 1999

December 2000

December 2001

December
End

April 1996

April 1997

April 1998

April 1999

April 2000

April 2001

April
Forcing from Arpege model

Duration

4 months

5 months

5 months

5 months

5 months

5 months

5 months
6 hourly analyses

6 hourly analyses

6 hourly analyses

6 hourly analyses

6 hourly analyses

6 hourly analyses

5 month winter mean

the duration of the experiments carried out in this study has been limited to 5 months (from December to April).

ii. Experiments. Although observations cover a longer period (since 1993), our interest focused on the period 1996 to 2001. This period was chosen because the atmospheric parameters data sets needed to drive Symphonie were not available before 1996. This period (1996 - 2001) is relevant because the highest seasonal means of particle flux are recorded within this period, at both depths and locations.

The model design imposed boundary conditions that were constant in time. As a consequence, we decided to concentrate on the winter period when the atmospheric forcing on the ocean circulation is most active and a strategy of ensemble simulations was adopted. Also, from December to April, $\geq 50 \%$ of the annual integrated particulate matter flux is recorded in Lacaze-Duthiers canyon and $\geq 60 \%$ in Planier Canyon, according to the computation of the Stability Flux Index (Guarracino, 2004).

Seven independent experiments were run (Table 1) with the same initial conditions and the same open boundary conditions as described above. Every experiment starts in December (except for winter 1996 which starts in January) and ends the following April. Experiments differ from each other only in the local atmospheric forcing, which is taken from the winters between 1996 and 2001. For the winter 1996 experiment, the model is integrated from January to April (and driven with atmospheric forcing corresponding to this period). For the winter 1997 experiment, the model is integrated from December 1996 to April 1997 and so on until the sixth experiment for winter 2001 (December 2000 to April 2001). A climatology experiment was also run, using a winter mean forcing that averaged all winters from 1996 to 2001. The major characteristics of these experiments are summarized in Table 1. This ensemble of experiments is used to assess the impact of atmospheric winter conditions on the GoL hydrodynamics in years 1996 to 2001.

iii. Modeling passive tracer. The circulation model did not include a particle transport model. A passive tracer was instead used to represent particulate matter. Therefore, every experiment listed in Table 1 includes the calculation of the distribution of a passive tracer. 
The purpose of the tracer calculation is to allow a relative comparison between the quantity of tracer exported from the shelf and the flux of particulate matter. The strategy employed integrates the tracer on a monthly basis since the observed particulate matter is the accumulation of matter in the trap for one month. This was achieved as outlined below.

An initial distribution for the passive tracer was defined with a uniform (horizontally and vertically) concentration inshore of the $150 \mathrm{~m}$ isobath (Fig. 1b) (no tracer is initially found offshore of this limit at any depth). During model integration (over a 5-month period), the tracer concentration is reset to initial distribution at the beginning of each month. Therefore, the quantity of the tracer, which is found at a depth greater than $150 \mathrm{~m}$ at the end of each month, represents the monthly export from the shelf. This quantity is vertically integrated to the depth of the sediment trap and the result, after normalization (see next section), is recorded as the shelf exported quantity of passive tracer and compared to particulate matter observations.

iv. Normalization, correlation and anomaly. Before comparing simulated shelf-exported quantities of passive tracer and particulate matter flux measurements, both quantities must be normalized. This is achieved by subtraction of the mean and division by the standard deviation. The comparison between time series of both quantities uses Pearson's coefficient correlation. Throughout the paper, variability of both quantities is investigated with respect to their time mean values (i.e. their time average from December-April and from 1996 to 2001). Time series of these anomalies are presented in Figure 4.

\section{Results and discussion}

\section{a. Validation of the model solution in the GoL}

The solution produced by the Gulf of Lion model in the winter 1998-1999 (December to April) has been convincingly validated against observations (Dufau et al., 2004). Our simulations differ from those of Dufau et al. (2004) only in the forcing fields. Solutions obtained for the various winters simulated (Table 1) compare well with the solution described by these authors, and the main characteristics of the general oceanic circulation are well reproduced. The Northern Current flows southwestward along the continental slope with a strength often reaching $40 \mathrm{~cm} \mathrm{~s}^{-1}$ (Fig. 3a). On the shelf, the model simulates the appearance of coherent cyclonic and anti-cyclonic eddies in relation with the dominant wind stress patterns as described by Estournel et al. (2003). The circulation on the shelf also features the formation of cold waters near the coast in late winter, and a thermal front is simulated at the shelf break with cooler waters on the shelf side (Fig. 3b). Winter current, temperature and salinity fields show significant interannual variability between 1996 and 2001. Therefore the major dynamical and hydrological features of the circulation of the GoL are at least, qualitatively represented by the model (Dufau et al., 2004; Estournel et al., 2003). 

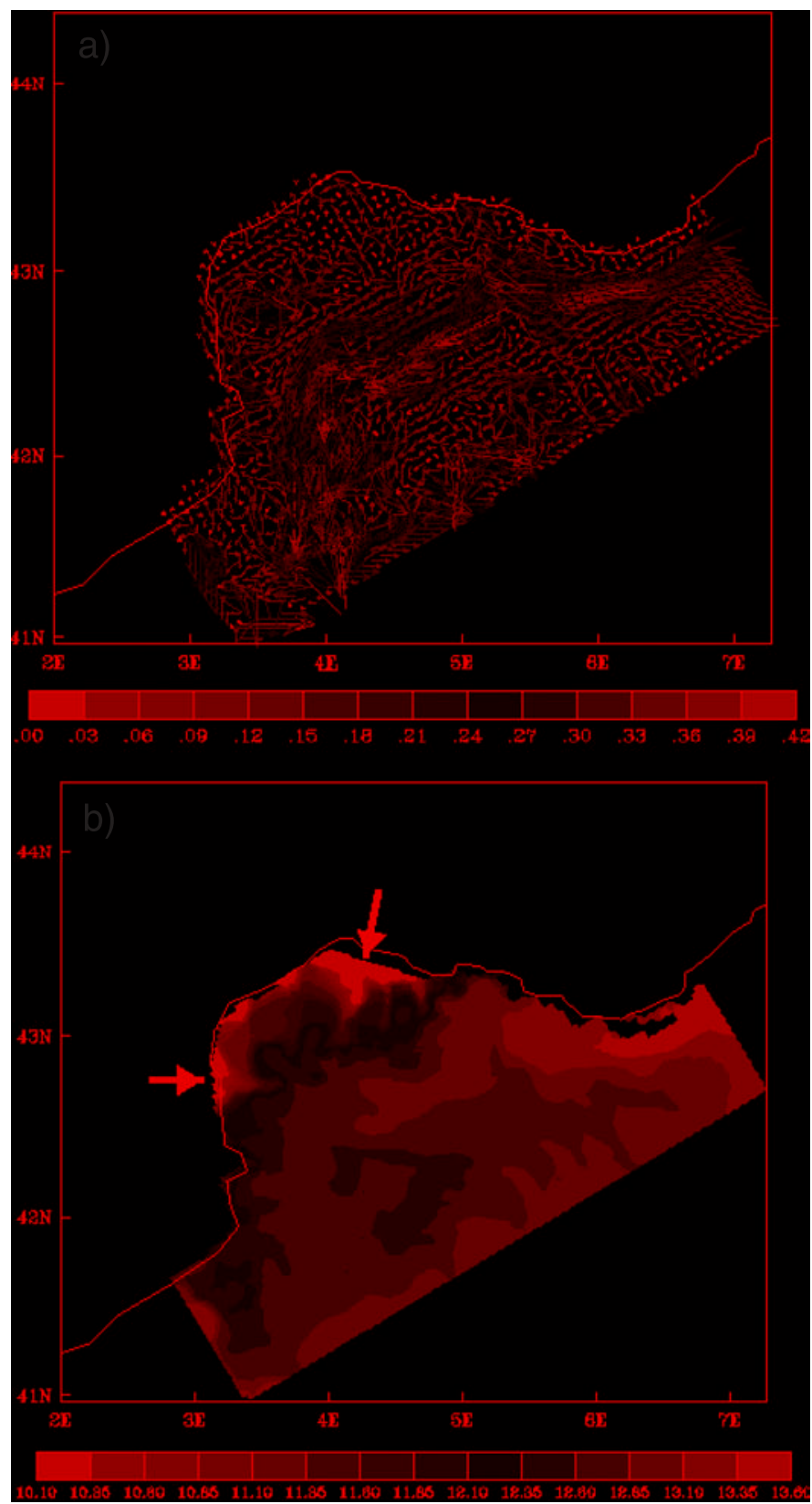

Figure 3. Distribution of the currents in $\mathrm{m} / \mathrm{s}$ (a), and temperature field in Celsius degrees (b) on the Gulf of Lion, at 30 meter depth on February 17, 1999. Black arrows show the formation of the dense water on the shelf, off Marseille and Languedoc-Roussillon coastlines. 


\section{b. Characterization of the origin of observed downward particle fluxes}

The origin of downward particle fluxes is probably related to many factors such as biological sources, shelf inputs and resuspension (Heussner et al., 2005). These various sources could contribute simultaneously to the sediment traps. The characterization of the origin of observed particle fluxes therefore helps in interpreting the modeling results.

The modeled tracer will represent mainly sources of matter on the shelf (Rhone inputs, wave-induced resuspension, and the Saharan dusts) in our simulations, since the lithogenic fraction is the dominant component of the particle flux in each location (more than $60 \%$ on average). Moreover the amount of lithogenic fraction increases with depth and varies little in comparison to particle flux variations at both seasonal and interannual scales (Guarracino, 2004). Microscopic analyses performed on material collected in February-March 1999 from the deeper trap at the exit of the GoL revealed a turbidity current source. At the entrance of the GoL, microscopic analyses revealed that both sediment traps caught material of common origin during this winter (Guarracino, 2004). These results will be analyzed in relation to the model dynamical response.

Biomarkers analysis such as sugars (Kerherve, 1996) and amino acids (Buscail, 1996) were performed on sediment trap samples from Oct.-1993 to Oct.-1994. These annual surveys revealed strong differences in the origin and the degradation rate of the particulate matter trapped at $500 \mathrm{~m}$ and $1000 \mathrm{~m}$ depth in each canyon. The export of the fresh reworked sedimentary material from the shelf to the slope (via submarine canyons) can be traced by the presence of $\beta$-aminoglutaric acid ( $\beta$-glu). Further investigations on sediment trap material could be carried out to find another amino acid representing the degradation state of sedimentary organic matter with more confidence (Dauwe et al., 1998). However, higher content of this substance is usually found in the upper few centimeters of oxic sediments near the river mouth and on the slope (Buscail, 1996). This signal was not found at $1000 \mathrm{~m}$ depth in the Lacaze-Duthiers canyon during this annual survey, nor was it found during the 1999 and 2001 wintertime periods (results not shown).

The sediment trap placed at $500 \mathrm{~m}$ depth at the GoL exit is dominated by material linked to the surface primary production and does not represent the shelf-slope exchanges of particles (Kerherve, 1996).

\section{c. Variability of observed downward particle fluxes}

Guarracino (2004) reported that variations of GoL particle fluxes are characterized by an East-West gradient and increase by a factor of 3 between the entrance (Planier Canyon) and the exit (Lacaze-Duthiers Canyon) of the GoL. Particle fluxes also increase with depth in both locations. At the exit, the trap $30 \mathrm{~m}$ above the bottom collected the highest monthly-integrated particulate flux during 1993-2001. Flux is maximal in February-March 1999 at $1000 \mathrm{~m}$ depth at the exit of the GoL and the quantity of particulate matter caught was underestimated since the trap cups overflowed.

Only a weak correlation was found between the shelf sources of particulate matter and particle fluxes. A strong correlation between shelf-slope exchanges considered in this study 
(northern current meanderings, winter dense-water formation) and particle fluxes measured on the slope was found, as well as between the Dyfamed time-series data (Chl- $a$ and Fucoxanthin-markers of diatoms, Marty et al., 2002) and the observed particle fluxes (Heussner et al., 2005; Guarracino, 2004).

The above analysis led us to formulate the following hypothesis: variations of the source of matter on the shelf, which mainly feed the shelf in winter, are not driving the export of matter to the open ocean. This export is likely controlled mainly by cross-shelf hydrodynamic processes such as the meandering of the Northern Current and the formation of dense water on the shelf in winter. This hypothesis is examined in the following sections in the light of the model results, that is, observed fluxes of particulate matter are compared to their model counterpart, the export of passive tracer from the shelf.

\section{d. Comparison of tracer export and observed particle fluxes at the scale of the Gulf of}

\section{Lion}

The variability in amount of simulated shelf-exported passive tracer can be compared with the total observed particle flux obtained from the accumulation of particle fluxes in the sediment traps.

Winter means of both quantities for 1996-2001 are very consistent (Fig. 4a), and reveal negative anomalies in December, January and April, and positive anomalies in February and March. Maximum export of tracer occurs in February a month before the observed peak in particle fluxes.

Interannual variability of simulated tracer export is less consistent with the observed particle fluxes - the correlation coefficient computed for both time series is only 0.25 (Fig. 4b). However, both series show that the maximum export of matter occurred during the 1999 winter. This maximum is not as marked in the model as in the observations: it is only $4 \%$ greater than the mean for the simulated tracer, whereas it represents $20 \%$ of the mean for the observed particle fluxes. The total quantity of tracer exported off the shelf to the open ocean varies from $20 \%$ to $40 \%$ of the initial tracer content from winter to winter. In the following, the model dynamics and variability will be used to investigate the dynamical factors controlling export of tracer from the shelf.

Time-series measurements of basin-averaged, simulated density (here $\sigma_{o}$ ) of shelf waters (i.e. waters inshore the $150 \mathrm{~m}$ isobath) are shown in Figure 5 for every simulated winter period and for the average solution of all experiments. Variations of this quantity, referred to as shelf-integrated density, are strongly related to densification of shelf waters under cold winter conditions, and thus may point out a link between passive tracer (or particulate matter) export and the process of dense water formation.

The shelf-integrated density (average see Fig. 5 a,b) remains rather constant in December and January, increases in February to reach a maximum in early March, then decreases back to near its initial value during March and April.

Year to year differences are shown in Figure 5a and 5b. Shelf waters reached their highest density ( $\sigma_{O}=28.8$ at the end of February) in the winter of 1999, when the ocean heat loss to the atmosphere is the greatest among all the years studied $\left(-83 \mathrm{~W} / \mathrm{m}^{2}\right.$, Table 2$)$. 

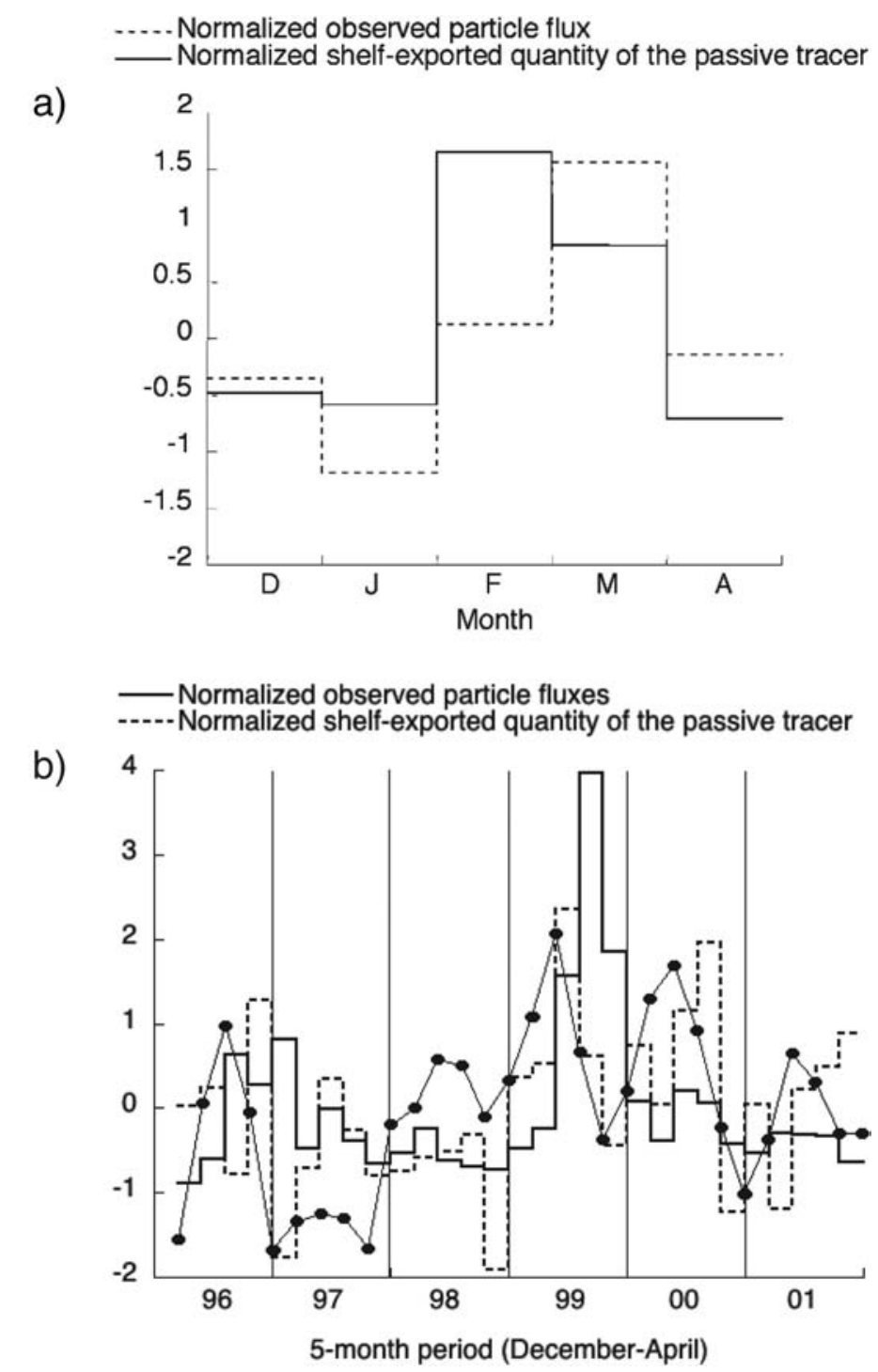

Figure 4. Comparison between normalized observed fluxes and integrated passive tracer over the shelf at different time scales. The mean seasonal cycle (a), and the 5-month interannual variability (b) are shown. The black dotted line represents the month average of the normalized shelf integrated density.

During the same winter, the simulated tracer export and observed particle fluxes exhibit their maximal values (Fig. 4).

Shelf waters are also dense in winter 2000, but the maximum density $\left(\sigma_{O}=28.7\right)$ is reached in early February. Note moreover that the 5-month average shelf-integrated density is higher in winter 2000 than in winter 1999. 
a)

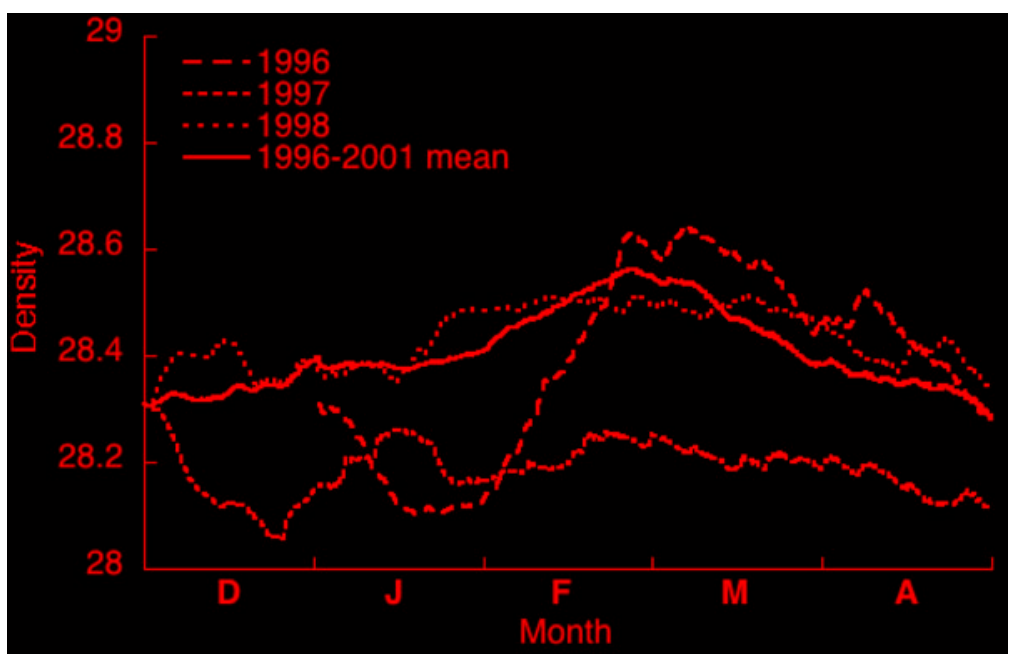

b)

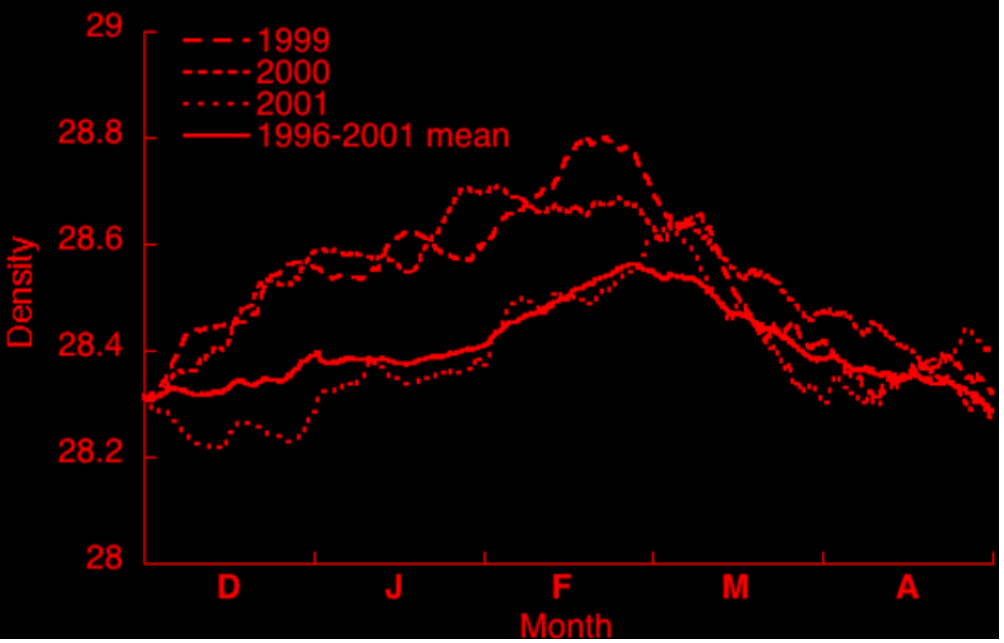

Figure 5. The time evolution of the simulated shelf integrated density for the simulated winter periods. (a) 1996, 1997, 1998 and the 1996-2001 mean, (b) 1999, 2000, 2001 and the 1996-2001 mean.

Winter 1997 is also atypical: the density of shelf waters is particularly low in December, due to intrusion of warm waters from the Northern Current, linked to the action of an anticyclonic eddy located at the entrance of the GoL (see Section 3f). Density remains more or less constant around $\sigma_{0}=28.2$ for the rest of the year, due to a significantly smaller heat loss to the atmosphere $\left(-15 \mathrm{~W} / \mathrm{m}^{2}\right.$, Table 2$)$. This winter exhibits a very small heat loss (Table 2).

Winter 1998 is also characterized by a smaller density value on the shelf. The highest densities in February and March are not greater than $\sigma_{O}=28.5$. Both 1997 and 1998 are 
Table 2. Annual mean net heat flux for the Gulf of Lion obtained from the Arpege model analyses and used to drive the ocean model. Negative values indicate a cooling of the ocean.

$\begin{array}{ccccccr}\text { Year } & 1996 & 1997 & 1998 & 1999 & 2000 & 2001 \\ \text { Net Heat Flux }\left(\mathrm{w} / \mathrm{m}^{2}\right) & -46 & -15 & -43 & -83 & -58 & -63\end{array}$

years of low export of tracer (or particle flux) and abnormally low ocean heat loss (Table 2).

The above results clearly establish a link, at the scale of the Gulf of Lion, between the intensity of ocean cooling, the density of shelf waters, and the export of passive tracer. This suggests that the process of dense water formation on the shelf could be an influential factor for the export of particulate matter to the open ocean. Note, however, that the correlation coefficient is low between the shelf integrated density and the simulated tracer export (0.54) and between the shelf-integrated density and the particle fluxes observed (0.27). Thus, the integrated shelf density may be not the only oceanographic process driving the time and space variability of the shelf tracer export.

\section{e. Comparison of tracer export and observed PM fluxes at observation points}

Local variability in amount of simulated shelf-exported passive tracer in mow compared with the observed particle flux the entrance of the GoL (Planier canyon) and at its exit (Lacaze-Duthiers Canyon) for the period from 1996 to 2001.

i. At the entrance in the Planier Canyon. The interannual variability of simulated tracer export and observed PM flux are very different in winter 1996 and winter 2001 (Fig. 6). The correlation coefficient between the two time series is negative and weak at both the $500 \mathrm{~m}(-0.17)$ and $1000 \mathrm{~m}$ depth (-0.08). Simulated tracer export does not show any significant vertical gradient, and is maximal in 1997 and 1998 at both $500 \mathrm{~m}$ and $1000 \mathrm{~m}$. It is negligible in the other years, except in 1996 at $1000 \mathrm{~m}$. Observed PM fluxes show important variations with depth, and maximum export occurs in different years: there are maxima in 1996, 1999, 2000 and 2001 at $500 \mathrm{~m}$, and the only maximum observed at $1000 \mathrm{~m}$ occurs in 1999. Note that the occurrence of a maximum export in March or April is quite robust at this location.

\section{ii. At the exit in the Lacaze-Duthiers Canyon. At $500 \mathrm{~m}$ in winters 1996 and 2001 (Fig. 7)} the variations of both the passive tracer export and the observed PM flux appear uncorrelated (coefficient correlation 0.04 as expected -see Section 3b). However both time-series show the highest export/fluxes in winter 1996 and high export/fluxes during the winters of 1999 and 2000 (Fig. 7a). Peaks occur generally earlier in the simulated export at this location. The relatively good agreement between observations and simulations can be explained by the fact that modeled dense waters flow along isopycnals, but not well through canyons at depth (Dufau et al., 2004). 


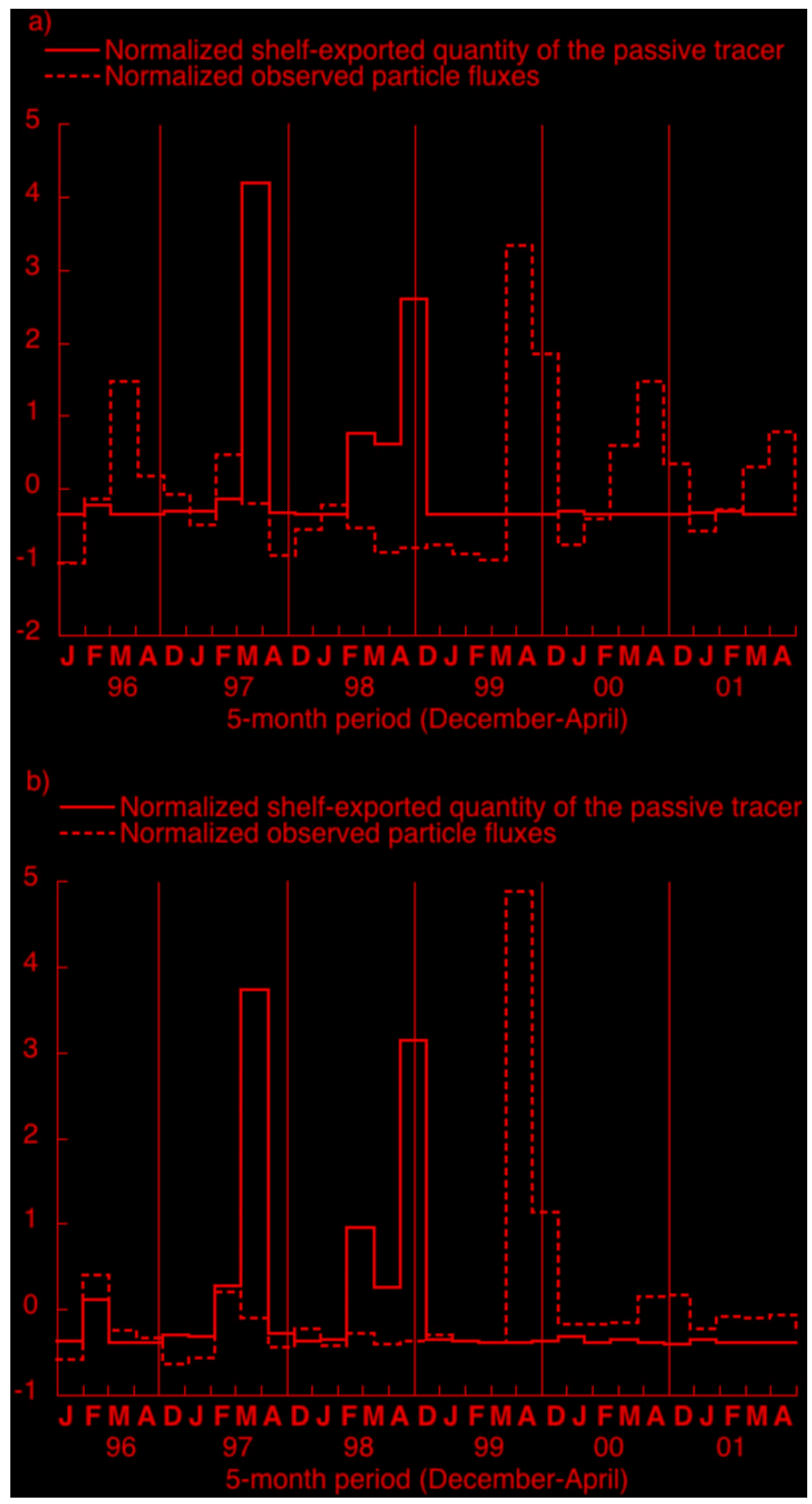

Figure 6. The comparisons of interannual variability of the normalized shelf-exported quantities of the passive tracer and the normalized particulate matter measurements in the Planier Canyon at 500 meter depth (a) and at 1000 meter depth (b). 
a)

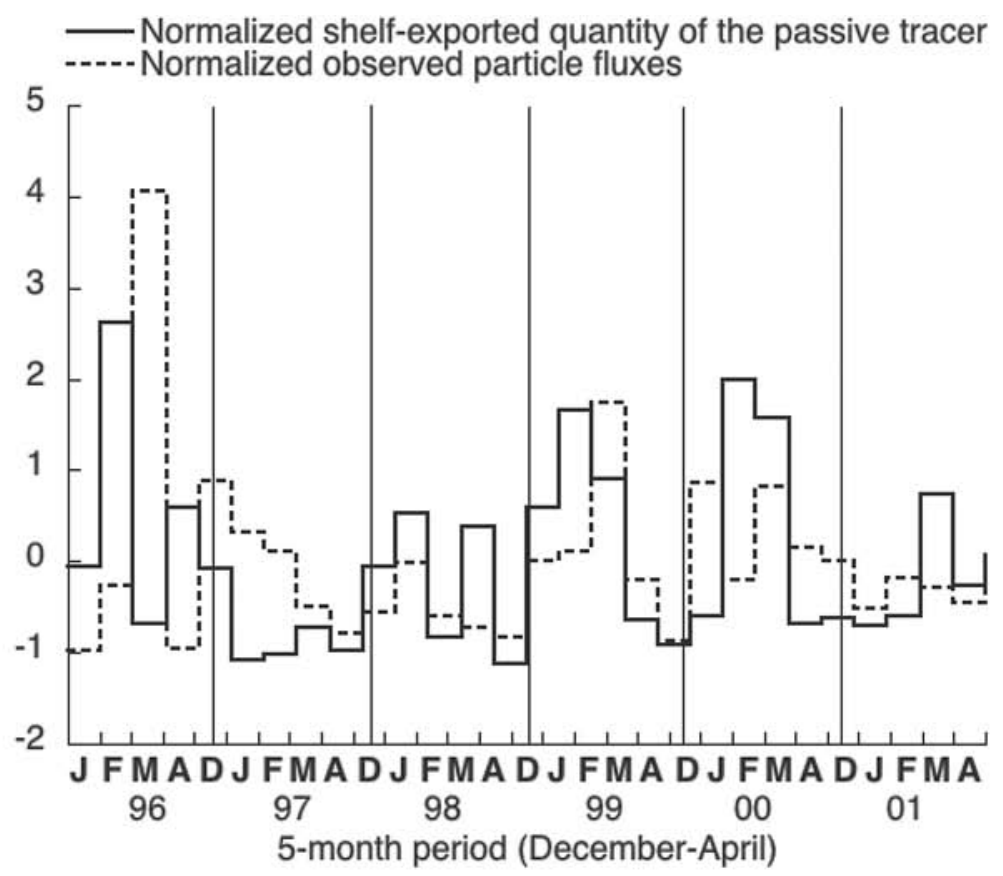

b) Normalized shelf-exported quantity of the passive tracer

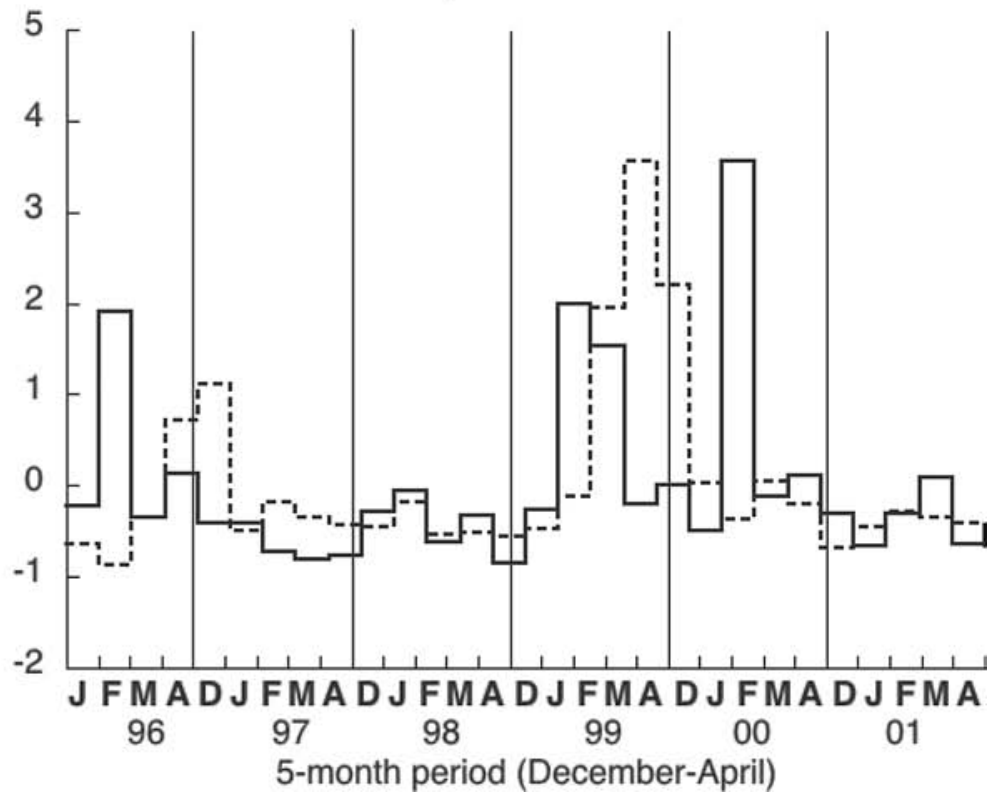

Figure 7. The comparisons of interannual variability of the normalized shelf-exported quantities of the passive tracer and the normalized particulate matter measurements in the Lacaze-Duthiers canyon at 500 meter depth (a) and at 1000 meter depth (b). 
At $1000 \mathrm{~m}$ depth, quantities of the passive tracer exported are the highest in the winter of 1999 and are the observations (Fig. 7b). However, some differences between model and observation at this depth could again explain the low correlation coefficient (0.08) computed between both time series. Tracer export is quite high in winter 2000, which does not fit observations (no anomaly of particulate matter flux has been measured in the winter of 2000). Simulated tracer export is also high in February 1996, but this high value does not correspond to high particle flux.

The east-west gradient in tracer export off the shelf has been checked out even if it doesn't appear in Figures 6 and 7 as the quantities have been normalized. Moreover since the passive tracer has no sinking velocity, the simulated tracer export is expected to be weaker than observed. Finally no increase of tracer export appears with depth, contrary to observations, at either sampling location. As the passive tracer reaches the bottom mainly through vertical downward movements (convection processes and downwelling), the horizontal advection of matter by the Northern Current (from the slope and other parts of the Mediterranean basin) could be a predominant process (and has not been simulated here).

The simulated export of tracer at $1000 \mathrm{~m}$ is particularly high in February and March 1999. This two-month period corresponds to the most dense shelf water production among all the winters (Fig. 5b). It is thus tempting to relate this peaking of the tracer export to dense water formation on the shelf. Abnormally dense waters formed on the shelf during winter 1999 would produce a stronger outflow in the canyons, driving a stronger flux of particles from the shelf to the deep ocean. However, the amplitude of the 1999 peak is considerably greater for the flux of particulate matter than for the export of passive tracer. Therefore, the simulated export does not appear to be large enough to convincingly explain the overflowing of the sediment traps of February/March 1999.

This indicates the following: (i) that the formation of dense shelf-waters may not be the only process responsible for the intense peak of particle flux recorded at this depth and (ii) that the response of the particle flux to the dense water forcing can be nonlinear, a peculiarity that cannot be captured by the simple representation of the particle flux with a passive tracer.

\section{f. Sources of interannual variability in the export of passive tracer from the shelf}

Four different wind patterns dominate the wind field during the 6-year study period (Fig. 8). These wind patterns are computed from the wind data used to drive Symphonie, and represent the wind stress curl. The first two patterns are associated with the dominance of Tramontane (type 1) and Mistral (type 2). These two have the greatest impact on the shelf dynamics and are associated with a strong east-west gradient of the wind stress curl, with negative curl to the south-west and positive curl to the northeast. Type 3 is associated with gusty winds from the East. The curl has an opposite sign and much less gradient than type 1 or 2 . Type 4 is characterized by low to no wind and no curl on the shelf and has a weak impact on shelf dynamics. 


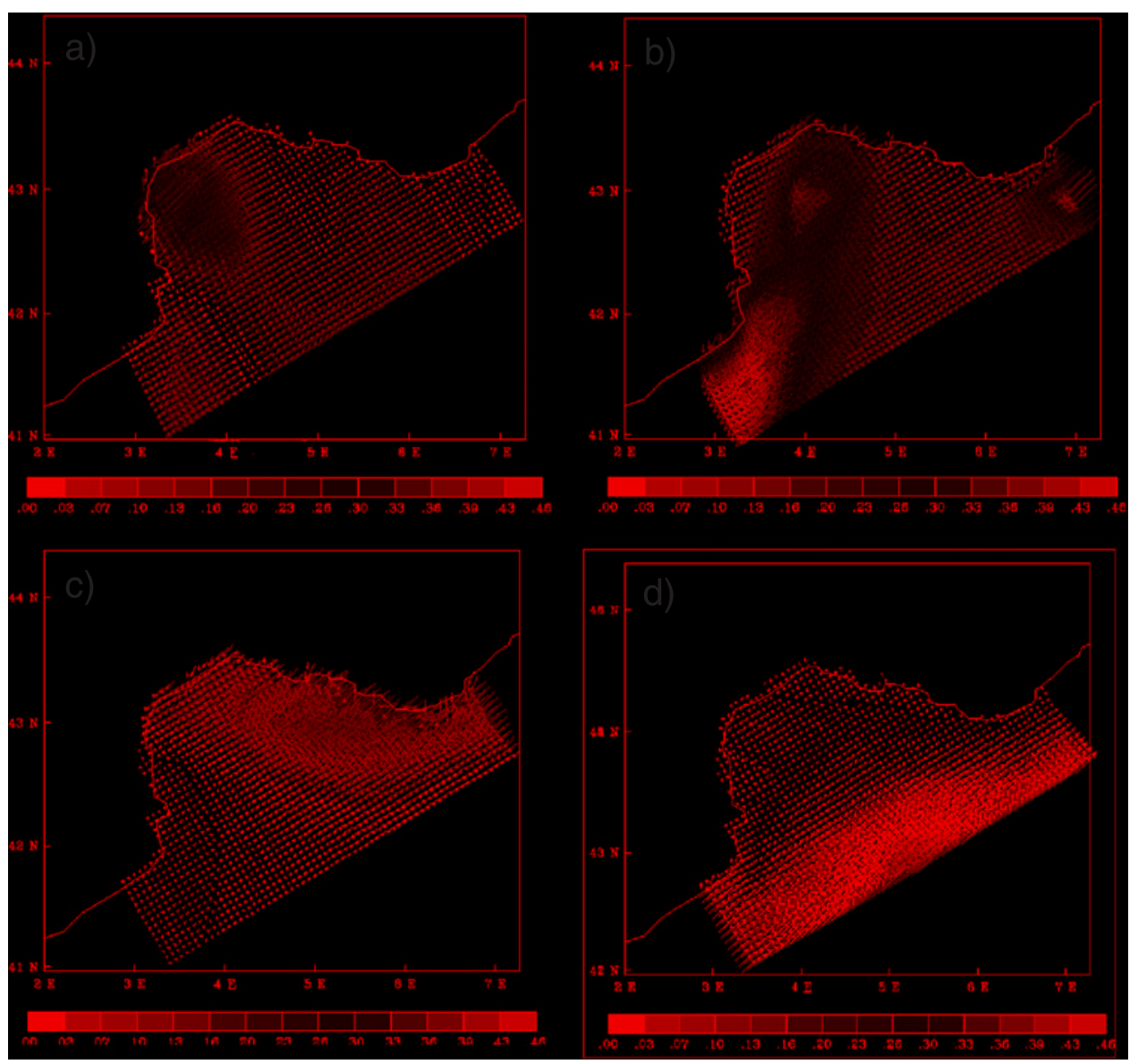

Figure 8 . The four main structures of the wind curl associated to the wind fields (in $\mathrm{m} / \mathrm{s}$ ) defined in this study (a) type 1 (b) type 2 (c) type 3 (d) type 4 . Wind pattern of type 1 is associated to Tramontane, wind pattern of type 2 is associated to Mistral, while wind pattern of type 4 is associated to easterly wind gusts. Finally wind pattern of type 4 represents a homogeneous wind field. The length of arrays is proportional to the intensity of the wind stress. In this figure, the coastline, traced by the visualization tool, is approximated for the GoL, and it does not match perfectly the bathymetry of Symphonie.

The 1997 and 1998 winters are characterized by a weak heat loss for the ocean (Table 2). As a consequence, weak convection and low density waters are expected on the shelf in winter (Fig. 5). This is consistent with the small values of simulated tracer export (and observed particle fluxes) seen at the exit of the GoL (Fig. 7). It is consistent with the large values of simulated tracer export seen at the entrance of the GoL (Fig. 6), which was not seen in the observation of particle fluxes. During both winters, type 3 winds appear most frequently from the beginning of December in 1997 during the 5-month period in 1998. 
This wind pattern implies the formation of an anticyclonic eddy in the eastern part of the GoL (Fig. 9 a,b). This eddy is not affected by the first wind type (not occurring or occurring weakly in February and March), during either winters. This eddy implies a greater export of the passive tracer from the shelf in the eastern part of the GoL. This dynamical structure helps to mix the cooler shelf water to the warmer waters of the Northern current and disappears during its progression to the Western part of the GoL. Thus the 1997 and 1998 winters are defined by the highest export of the passive tracer from the shelf but only in the eastern part of the GoL although this was not observed in particle flux (Fig. 6). The difference between observations and simulations could have been caused by the poor model representation of the interannual variability of the Northern Current at the the entrance of the GoL.

In contrast the 1999 winter is characterized by intense atmospheric forcing. This leads to an important transfer of heat from the ocean to the atmosphere $\left(83 \mathrm{~W} / \mathrm{m}^{2}\right.$, Table 2) and shelf waters are particularly dense from January to March (Fig. 5b). This event was also well simulated in the work of Dufau et al. (2004). The amount of simulated tracer exported from the shelf in 1999 is maximum at the exit of the GoL (as shown in Figs. 6 and 7). In fact, the model does not predict any export at the entrance in 1999, in direct contradiction to the observations. The winter of 1999 is dominated by an abnormally high appearance of wind patterns 1 and 2 (80\% of the time in December, 50\% in January, 100\% in February and $80 \%$ in March and April). This implies a quick progression of the cooled and dense shelf waters seaward and a significant western flow of this dense water until March. The same scenario takes place in 2000 but the formation of dense water happens sooner in the western part of the Gulf as the type 1 structures are more frequent in December and January than during the 1999 winter. This explains the high export of the passive tracer simulated in January 2000 in the western part of the Gulf. During the 1999 and 2000 winters the export of the shelf dense water in the Western part of the Gulf is made possible as the Northern Current is pushed seaward whereas its position remains close to the continental slope in the eastern part of the GoL (Fig. 10a, b). The position of the Northern Current at the depth of the sediment traps appears to be driven by the shelf circulation induced by the wind. The wind patterns prevailing in winter 1999 do not allow the formation of an anticyclonic eddy in the eastern part of the GoL. As the Northern Current is not forced by any recirculation on the shelf, it remains close to the slope acting as a barrier to tracer export. Thus the exportation of the dense shelf water explains the export of the passive tracer from the shelf.

The 2001 winter is characterized by a rather high annual heat loss $\left(-63 \mathrm{~W} / \mathrm{m}^{2}\right)$, but the density of shelf waters remains low, except in March (Fig. 5). The wind pattern of type 3 is dominant in December (60\%), January (80\%) and March (40\%), and significant in February (20\%). This is at the expense of the wind pattern type 2 whose occurrence is the lowest for all winters considered.

Such a dominance of the type 3 wind pattern is very specific to winter 2001. This wind pattern (easterly winds) does not push the Northern Current offshore. In addition there is a strong deficit in the occurrence of the Mistral (type 2 pattern). Consequently, the Northern 


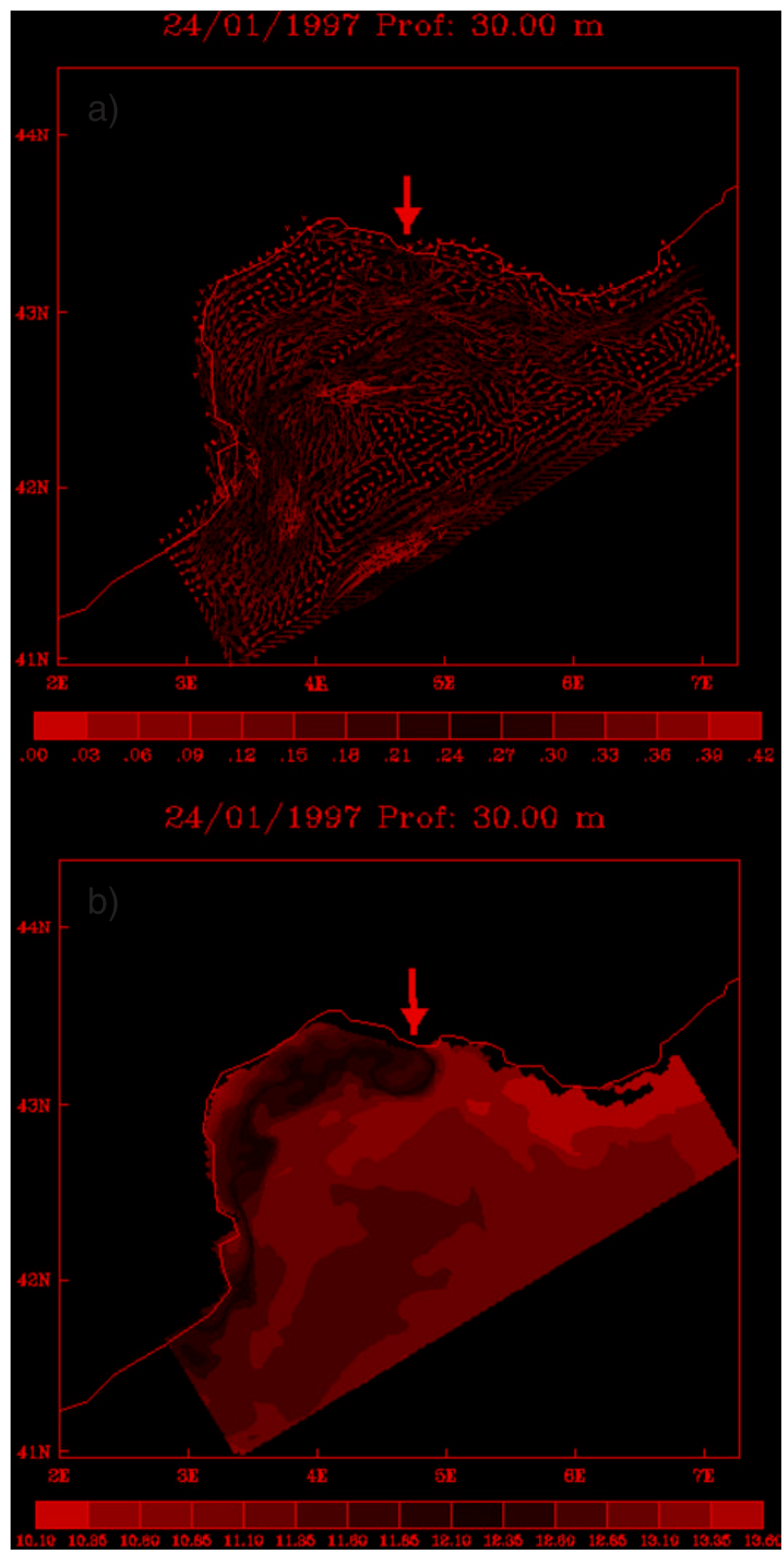

Figure 9. Distribution of the currents in $\mathrm{m} / \mathrm{s}$ (a), and temperature field in Celsius degrees (b) on the Gulf of Lion, at 30 meter depth on January 24, 1997. Black arrows represent the anticyclonic eddy at the entrance of the GoL. 


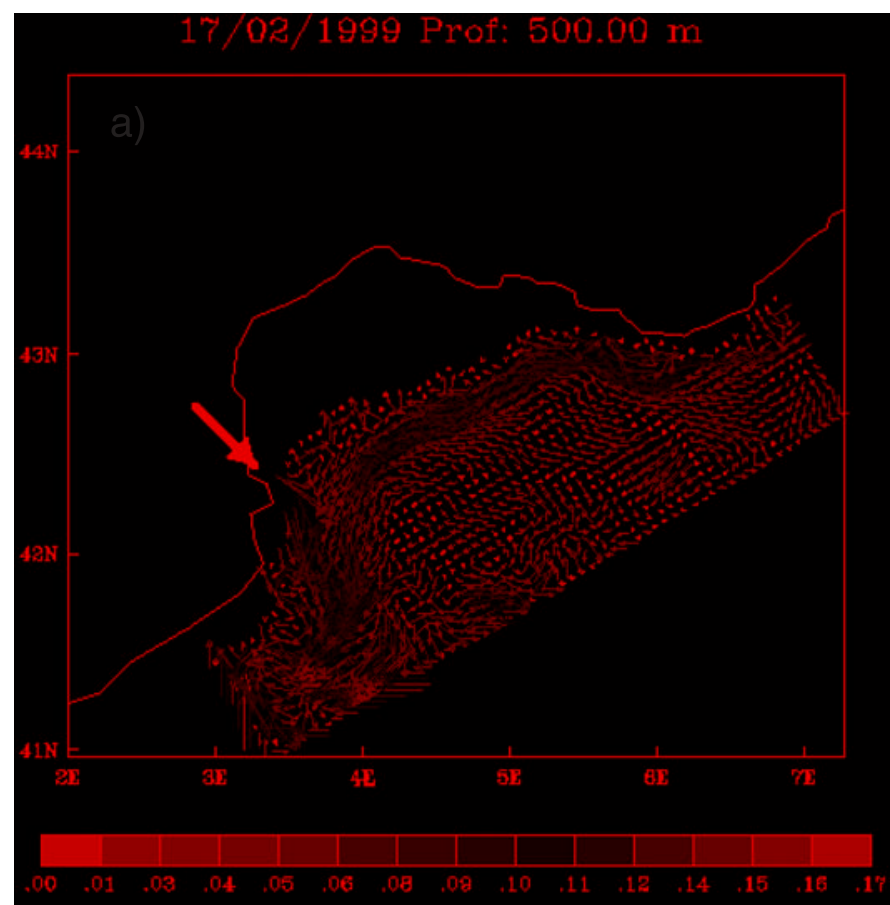

\section{7/02/1999 Prof: $500.00 \mathrm{~m}$}

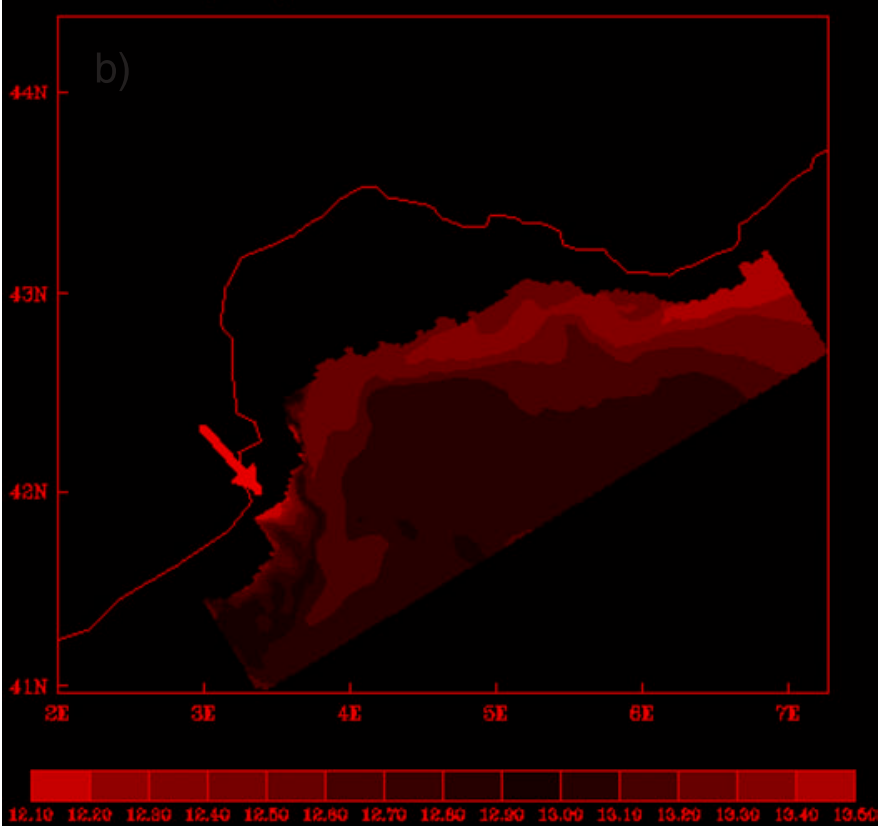

Figure 10. Distribution of the currents in $\mathrm{m} / \mathrm{s}$ (a), and temperature field in Celsius degrees (b) on the Gulf of Lion, at 500 meter depth on February, 1999. Black arrows represent the spread of the shelf dense water at depth and at the exit of the GoL. 


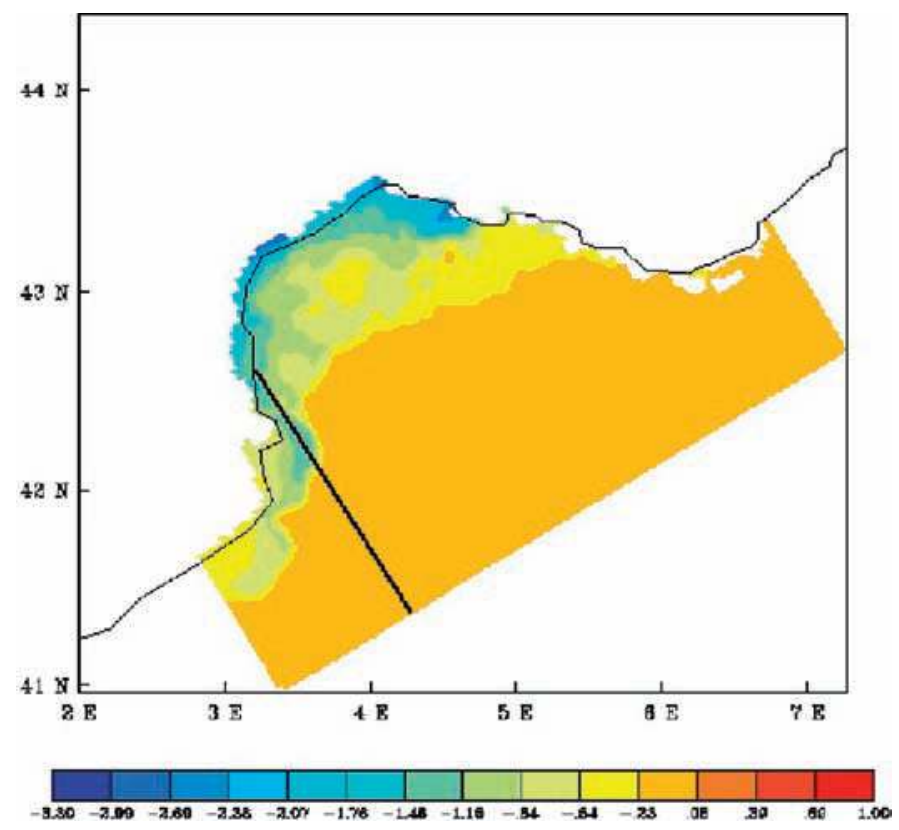

Figure 11. The monthly mean water temperature anomaly in the Gulf of Lion for the 1996 to 2001 winters. This 1996-2001 5 month-period mean water temperature anomaly is shown for the deeper sigma-level of the Symphonie model. The black line represents the section considered to explore the interannual variability of the spread of shelf dense waters at depth. In this figure, the coastline, traced by the visualization tool, is approximated for the GoL, and it does not match perfectly the bathymetry of Symphonie.

Current remained confined to the shelf break during winter 2001, which did not favor the export of the passive tracer away from the shelf.

In the eastern part of the GoL, major particulate matter inputs could come mainly from the advection of the Northern Current at both depths. Shelf waters could export matter only intermittently and mainly during winters defined by a weak convection activity. At these times, the Northern Current could act as a barrier to the offshore propagation of coastal waters, especially during winters defined by strong dense water formation. This is consistent with a homogeneous transfer of carbon to depth analyzed in the winter of 1999.

A clear positive correlation between the density of shelf waters and the export of passive tracer, at least at the exit of the GoL (the Lacaze-Duthiers Canyon) has been established. To better understand the physical process responsible for this correlation, and specifically the 1999 extreme export event, the circulation path of the coldest shelf waters is now examined.

The export of the coldest water to depth is significant in the western part of the Gulf (Fig. 11). Furthermore the coldest shelf water appears close to the coasts off Provence and off Languedoc-Roussillon. 
Near the Lacaze-Duthiers canyon the 1997 winter where moderate atmospheric conditions and a weak shelf dense water formation prevail was quite distinct from the 1999 winter defined by both strong atmospheric conditions and oceanic convection. The spatial evolution of the monthly mean temperature (MMT hereafter) anomaly is quite different from December to April 1997 and in 1999 (see Fig. 12 for March 97 and March 99 situation). The negative MMT anomalies appear on the shelf and in the benthic boundary layer in December 1999 whereas colder waters remain close to the subsurface and on the shelf in December 1997. Cold waters then progress seaward close to the slope up to the $500 \mathrm{~m}$ depth in January and February 1999 whereas the majority of positive MMT anomalies are found on the slope in 1997. In January and February 1997 the export of the coldest water from the shelf to the slope is not significant. The mean temperature minimum recorded on February 19th 1999 at 1000 m depth in the axis of the Lacaze-Duthiers canyon is not revealed in the vertical structure of the MMT anomaly. A positive MMT is found from $500 \mathrm{~m}$ to $1000 \mathrm{~m}$ depth.

The negative MMT anomalies are large in March 1999 between $500 \mathrm{~m}$ and $700 \mathrm{~m}$ depth whereas the positive MMT anomalies are extended into the shelf and the slope in March 1997. The cold dense water export appears to be significant at the monthly level in February and March 1999. Nevertheless the MMT doesn't reveal a homogeneous spatial distribution in March 1999 (Fig. 12b). The cooling of the water column near the Lacaze-Duthiers canyon doesn't reach $1000 \mathrm{~m}$ depth since the positive MMT anomalies values appear at $800 \mathrm{~m}$ depth and at the shelf break (Fig. 12b).

We conclude that the temperature minimum recorded at $1,000 \mathrm{~m}$ depth by the current meter placed in this canyon axis can't be explained by a homogeneous oceanic convection process. In the western part of the GoL, the dense waters flows on the shelf exhibit a well-marked interannual variability. Nevertheless the sediment trap placed at mid-depth in the water column was not moored at the best place to collect significant shelf matter inputs. At 1,000 $\mathrm{m}$ depth, the sediment trap does not collect significant present-day inputs from the shelf since 1993, and the overflow observed in winter of 1999 is suspected to be due to a turbidity current (as highlighted by microscopic analysis, see Section 3.b), probably activated by the flow of shelf dense waters. The material caught during this exceptional event is still not directly linked to the shelf inputs at a comparable time scale. This scenario is consistent with the absence of a link in the origin of the material caught by sediment traps, along the mooring line.

\section{Conclusion}

Although the comparison between observations and simulations is confounded by different sources of bias identified from both the modeling approach and from the particle fluxes data, our results suggest that the explanation for the model data discrepancy could come from a poor functioning of the sediment traps since October 1993. During the periods investigated, the sediment traps appear to be mainly fed by the advective lateral inputs of matter. This matter doesn't originate in the shelf waters. Also the sediment traps placed in both canyons axis do not 


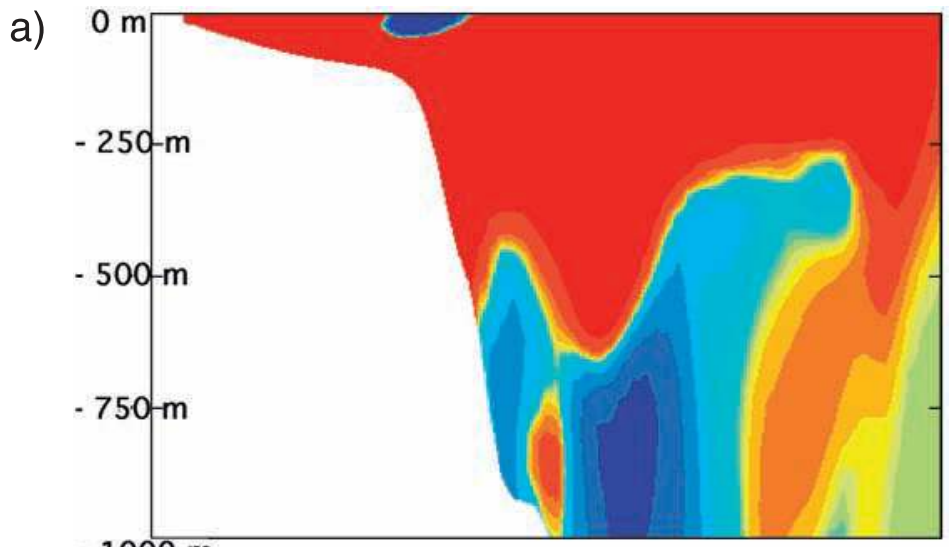

$-1000 \mathrm{~m}$
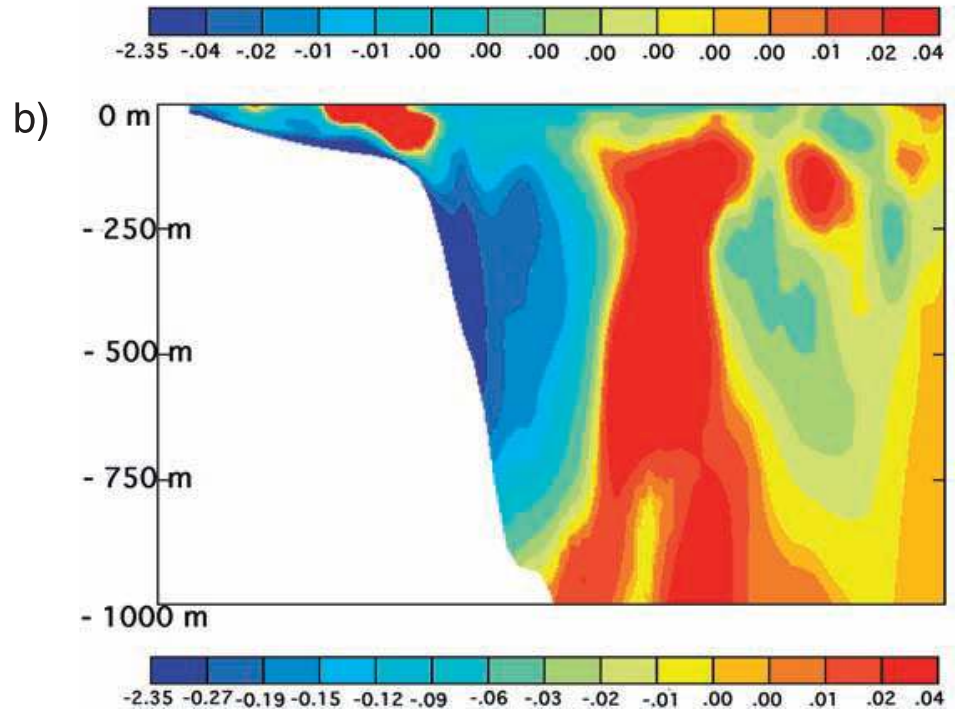

Figure 12. The monthly temperature anomaly section near the Lacaze-Duthiers canyon in (a) March 1997 and (b) March 1999.

measure as significant a vertical particle flux as they should. The present-day exportation of matter from the shelf to the slope is not measured according to the chosen experimental strategy. These long-term time series of particle fluxes could be revisited in regard to other geological time scales, especially for the deeper traps at both locations.

A future long term monitoring of present-day export of matter from the shelf will require sediment traps placed at the canyon heads, with a sampling frequency fitted to short term and brief events occurring on the shelf, such as resuspension due to storms. The use of another experimental strategy leaving the canyon axis (to take into account possible hydrodynamics effects in sedimentation within the canyon), and the use of biomarkers 
could be useful to determinate the freshness of the sediment, and to better understand the processes governing the exportation of matter from the shelf to the slope.

Acknowledgments. The experimental strategy was chosen by the scientists of the Centre de Formation et de Recherche sur l'Environnement Marin (CEFREM) in 1993. The technical staff of the CEFREM has carried out the sample collection and their treatment. This work would not have been possible without the financial support of the 'Ministère français de l'Enseignement supérieur et de la Recherche' to MG. This author wishes to particularly thank Dr. J.-M Molines for his help in computer science, and Dr. R. Buscail for her strong communication skills. Finally, the authors thank anonymous reviewers for their helpful comments.

\section{REFERENCES}

Bethoux, J.-P., X. Durrieu de Madron, F. Nyffeler and D. Tailliez. 2002. Deep water in the western Mediterranean: Peculiar 1999 and 2000 characteristics, self formation hypothesis, variability since 1970 and geochemical inference. J. Mar. Syst., 33-34, 117-131.

Berne, S., J.-C. Aloisi, J. Batzan, B. Denneliou, L. Droz, T.A. Dos Reis, Y. Lofi, Y. Mear and M. Rabineau. 2002. Carte morpho-bathymetrique du Golfe du Lion au 1/100 000, notice explicative, in Carte et Atlas, $48 \mathrm{pp}$.

Biscaye, P. E. and R. F. Anderson. 1994. Fluxes of particulate matter on the slope of the Southern Middle Atlantic Bight: SEEP- II. Deep-Sea Res. II, 41, 459-509.

Buscail, R. 1987. Etude de la matiere organique dissoute sur la marge continentale du Golfe du Lion, Doctoral thesis, University of Perpignan, 600 pp.

- 1996. The amino acids in sediment trap material as tracers of sources and degradation of organic matter, in Euromarge Northwestern Mediterranean Final Report Mast II Programme, M. Canals, J. L. Casamor, I. Cacho, A. Calafat and A. Monaco, eds., Fundacio "Boschi i Gimpera" from Universitat de Barcelona, Department de Geologia, Dinamica, Geofisica i Paleontologia, Barcelone (Espagne).

Conan, P. and C. Millot. 1995. Variability of the Northern Current off Marseilles, western Mediterranean Sea, from February to June 1992. Oceanologica Acta, 18, 93-205.

Dauwe, B. and J. Middelburg. 1998. Amino acids and hexosamines as indicators of organic matter degradation state in North Sea sediments. Limnol. Oceanogr., 43, 782-798.

Déqué, M., C. Devreton, A. Braun and D. Cariolle. 1994. The ARPEGE/IFS atmosphere model: a contribution to the French community climate modeling. Climate Dyn., 10, 249-266.

Dufau, C., P. Marsaleix, A. Petrenko and Y. Dekeyser. 2004. 3D modeling of the Gulf of Lion's hydrodynamics during January 1999 (MOOGLI 3 experiment) and late winter 1999: WIW formation and cascading over the shelf break, J.Geophys. Res., 10(C11), C11002, doi: 10.1029/ 2003 JC 002019.

Estournel, C., X. Durrieu de Madron, P. Marsaleix, F. Auclair, C. Julliand-Dufau and R. Vehil. 2003. Observation and modelisation of the winter coastal oceanic circulation in the Gulf of Lions under wind conditions influenced by the continental orography (FETCH experiment). J. Geophys. Res., 108(C3), 8059, doi: 10.1029/2001 JC 000825.

Guarracino, M. 2004. Contrôle hydrodynamique du transfert de la matière particulaire sur la marge continentale du Golfe du Lion, Doctoral thesis, University of Perpignan, $230 \mathrm{pp}$.

Heussner, S., J. Carbone and J. Ratti. 1990. The PPS 3 time-series sediment traps and the traps processing techniques used in the ECOMARGE experiment. Cont. Shelf Res., 10, 943-958.

Heussner, S, X. Durrieu de Madron, A. Calafat, M. Canals, J. Carbonne, N. Delsaut, M. Guarracino and G. Saragoni. 2005. Spatial and temporal variability of downward particle fluxes on a continental slope: lessons from an 8-yr experiment in the Gulf of Lions (NW Mediterranean). Mar. Geol., (submitted). 
Kerherve, P. 1996. Les monosaccharides marqueurs de l'origine et de l'etat de degradation de la matiere organique particulaire en milieu marin, Doctoral thesis, University of Perpignan, $230 \mathrm{pp}$.

Klinck, J. M. 1996. Circulation near submarine canyon: a modeling study. J. Geophys. Res., 101(C1), 1211-1223.

Lampitt, R. S., B. J. Bett, K. Kiriakoulaki, E. E. Popova, O. Ragueneau, A. Vangrieshiem and G. A. Wolff. 2001. Material supply to the abyssal seafloor in the Northeast Atlantic. Prog. Oceanogr., 50, $27-63$.

Liu, K.-K, L. Atkinson, R. Quinones and L. Talaue-MacManus. 2003. Carbon and Nutrients Fluxes in Continental Margins: A Global Synthesis, Springer Verlag, NY, 300 pp.

Marty, J.-C., J. Chiaverini, M.-D. Pizay and B. Avril. 2002. Seasonal and interannual dynamics of nutrients and phytoplankton pigments in the Western Mediterranean Sea at the Dyfamed time-series station (1991-1999). Deep-Sea Res. II, 49, 2125-2141.

Millot, C. 1990. The Gulf of Lion's hydrodynamics. Cont. Shelf Res., 10, 885-894.

Miquel, J.-C, S. W. Fowler, J. La Rosa and P. Buat-Menard. 1994. Dynamics of the downward flux of particles and carbon in the open northwestern Mediterranean Sea. Deep-Sea Res. I, 41, 242-261.

Miquel, J.-C and J. La Rosa. 1999. Suivi a long terme des flux particulaires au site Dyfamed, Oceanis, 25, 303-318.

Monaco, A., X. Durrieu de Madron, O. Radakovitch, S. Heussner and J. Carbonne. 1999. Origin and variability of downward biogeochemical fluxes on the Rhone continental margin (NW Mediterranean), Deep-Sea Res. I, 46, 1483-1511.

Monaco, A., S. Heussner, T. Courp, R. Buscail, S. W. Fowler, C. Millot and F. Nyffeler. 1987. Particle supply by nepehloid layer on the Northwestern Mediterranean margin, in SCOPE/UNEP Sonderband, Mltt. Geol.-Palaont. Inst., Univ. Hamburg.

Sammari, C., C. Millot and L. Prieur. 1995. Aspects of the seasonal and mesoscale variability of the Northern Current in the western Mediterranean Sea inferred from PROLIG-2 and PROS-6 experiments, Deep-Sea Res. I, 42, 893-917.

U.S. JGOFS. 1989. Sediment Trap Technology and Sampling, Report of the U.S. JGOFS, Planning Report Number 10,Working Group on Sediment Trap Technology and Sampling, George Knauer and Vernon Asper (Co-Chairmen), U.S. JGOFS Planning Office, Woods Hole, MA, 94 pp.

Van Weering, T. C. E, I. N. McCave and I. R. Hall. 1998. Ocean Margin Exchange (OMEX I) benthic processes study, Prog. Oceanogr., 42, 1-4.

Von Storch, H. and F. W. Zwiers. 1997. Statistical Analysis in Climate Research. Cambridge University Press, 484 pp.

Wong, C. S., F. A. Whitney, D. W. Crawford, K. Iseki, R. J. Matear, W. K. Johnson, J. S. Page and D. Timothy. 1999. Seasonal and interannual variability in particle fluxes of carbon, nitrogen and silicon time series of sediment traps at ocean station P, 1982-1993: relationship to changes in subarctic primary productivity, Deep-Sea Res. II, 46, 2735-2760. 